\title{
Nuevos debates, nuevas ideas y nuevas prácticas en la psicología social de la era 'post-construccionista'
}

\author{
Lupicinio Íñiguez \\ Universitat Autònoma de Barcelona \\ lupicinio.Iñiguez@uab.es \\ http:/lantalya.uab.es/liniguezl
}

Puede afirmarse que la Psicología Social contemporánea dominante ha perdido cualquier interés por el debate intelectual. Y no sólo eso, sino que como decía Henry Tajfel 'la Psicología social no ha tenido ciertamente éxito en crear una revolución intelectual en el sentido de afectar profundamente nuestra visión de la naturaleza human como, por ejemplo, Freíd y Piaget lo han hecho para la psicología individual' (Tajfel, 1972:106).

Sin embargo, ha sido el Construccionismo social quizás la única corriente que se ha erigido como uno de los interlocutores en los debates contemporáneos de la Filosofía y de las Ciencias Sociales.

Efectivamente, en los años ochenta del siglo pasado, este tipo de perspectiva penetra en el conjunto de las Ciencias sociales y, específicamente, en la Psicología social y se convierte en revulsivo en un contexto disciplinar marcado por una ortodoxia heredera del positivismo. Encuentra una fuerte oposición y las voces en contra se alzan potentes y descalificadoras, llegando a la amenaza de exclusión, cuando no a la exclusión misma, de todas aquellas personas que se sentían atraídas por este programa.

La cuestión ahora es, después de más de veinte años, ¿aún mantiene el construccionismo la misma carga de rebeldía? O por el contrario ¿estamos delante de una nueva forma de ortodoxia?

Hay algunos problemas, pero creo que desde el construccionismo se pueden aventurar algunas de las claves que se encuentran en el paisaje post-construccionista una vez sentidos algunos desasosiegos, algunos malestares, algunos problemas incluso, que pueden derivarse de la "época dorada" construccionista.

En todo caso, se trata de mantener en permanencia una perspectiva crítica en Psicología social. Perspectiva crítica en lo teórico, pero también el estudio específico de procesos sociales y, por qué no también, en la intervención. Lo que habría que hacer sería perfilar un panorama dónde aún tengan cabida aportaciones que subviertan el carácter instituido y objetivo de las ciencias sociales partiendo del posicionamiento de que la autoridad científica es, en estos momentos, la autoridad con mayor poder a la hora de justificar el mantenimiento de un orden social, de legitimar órdenes sociales con efectos de sujeción y dominación de las personas. 


\section{El punto de vista socioconstruccionista}

Creo honestamente que nunca ha estado demasiado claro, sobretodo entre sus críticos, qué es o en qué consiste eso que se llama "construccionismo". La crítica fácil, que ha dominado desde el inicio, lo ridiculiza desde la estrambótica idea de que su esencia misma no es sólo que afirme que todo es una construcción social, sino, sobretodo, que es una construcción lingüística. Tal ridiculización utiliza como tropo retórico la celebrada idea de que los/as construccionistas desatienden las limitaciones y constricciones que impone la realidad material.

Pero el construccionismo, o mejor -para no reificar- la perspectiva construccionista no es exactamente eso. Lo que quiero decir es que al decir esto, el sufijo "ismo" tiene el efecto discursivo de reificar un proceso, haciendo aparecer algo como una "escuela" de pensamiento, o una "nueva teoría". Esta perspectiva es algo más complejo, con bastantes más matices que convendría señalar y tener en cuenta. A pesar de ello, es bien cierto que no se puede ofrecer una definición única de "construccionismo social". Mas bien, se pueden detallar ciertos elementos y supuestos que, vistos en conjunto, podrían representar esa "perspectiva", o como ha dicho Tomás Ibáñez (1994) ese "movimiento".

Los elementos y supuestos de esta "perspectiva" o "movimiento" constituyen una amplia y abierta lista. Y, además, contra lo que se puede suponer a partir de las críticas "desde fuera", nada homogénea pues como dice Vivian Burr (1997), no se puede afirmar que haya ningún elemento sine qua non que determine la adscripción de un autor o autora al "construccionismo social".

Si hay algo que se pueda identificar como característica principal, ésta sin duda es su posición crítica, su posición de continuo cuestionamiento de aquello que venimos considerando como obvio, correcto, natural o evidente.

Podríamos decir que los elementos que definen una posición construccionista son: antiesencialismo (las personas y el mundo social somos el resultado, el producto, de procesos sociales específicos); relativismo (la "Realidad" no existe con independencia del conocimiento que producimos sobre ella o con independencia de cualquier descripción que hagamos de ella); el cuestionamiento de las verdades generalmente aceptadas (el continuo cuestionamiento de la "verdad", poniendo en duda sistemáticamente el modo cómo hemos aprendido a mirar el mundo y a mirarnos a nosotros mismos); determinación cultural e histórica del conocimiento, y el papel conferido al lenguaje en la construcción social (La realidad se construye socialmente y los instrumentos con los que se construye son discursivos).

Ahora bien, después de algún tiempo hemos podido caer en una cierta complacencia con el "ideario construccionista" convirtiéndolo en una especie de "nueva ortodoxia". Entiendo que un talante crítico debe huir de esta clase de complacencia. Sin embargo, antes de pasar a dibujar algunos elementos del nuevo paisaje "post-construccionista" me gustaría señalar algunas características que han sido útiles en la empresa construccionista y que creo pueden ser todavía útiles en el futuro. Son características que relacionadas con una forma de entender al ser humano que merecen ser tenidas en cuenta: la historicidad de nuestro conocimiento y el carácter interpretativo del ser humano

En primer lugar hay que extraer consecuencias del carácter histórico del conocimiento. Asumir plenamente el sentido de la historicidad y que el papel de las ciencias y de sus objetos no se reduce a una propuesta de explicación lineal de la constitución del presente, abre la posibilidad de pensar el presente pero también la de construir futuros distintos. 
Por ello, enfocar genealógicamente el estudio de un objeto de conocimiento nos permite comprender nuestro presente, resaltando al mismo tiempo que su repetición no es obligatoria en el futuro.

En segundo lugar, hay que subrayar el carácter interpretativo del ser humano. Ningún proceso social, y específicamente ni la Ciencia ni el sujeto pueden darse sin interpretación, pues nuestro conocimiento del mundo y de nosotros/as mismos/as está vinculado a la interpretación que realizamos desde el marco lingüístico y cultural en el que nos desenvolvemos. No es posible entonces delimitar la objetividad del sujeto sin la interpretación y sin que medie el juego hermenéutico.

\section{¿En qué se ha equivocado el construccionismo?}

Bien. Quizás el construccionismo se ha acomodado y ha devenido en mainstream, casi sin darse cuenta, o al menos eso ha sido así en algunos lugares del mundo. La pregunta es ise ha equivocado el construccionismo?

Quizás sí. Probablemente la acrítica acomodación a la paulatina institucionalización del construccionismo social. En efecto, de lo que no cabe la menor duda es que en tan solo dos décadas este movimiento ha pasado de ser un marginal en las ciencias sociales y en la Psicología social, para pasar a ser una perspectiva reconocible y reconocida, con sus propios medios de comunicación y difusión, recursos públicos para investigación, etc. $Y$ a este proceso no se ha posicionado siempre de forma crítica y contundente sino, frecuentemente con un talante conformista y acomodaticio. Si hace 20 años defender una tesis doctoral en este tipo de perspectiva era un acto heroico, hoy es, en algunos ámbitos, una marca de distinción y una garantía de promoción profesional y académica.

Desde mi punto de vista, algunos supuestos constitutivos del construccionismo pueden mantenerse. Otros deben atender a las críticas que se le han hecho en los últimos años. Pueden asumirse perspectivas nuevas. Y, finalmente, puede re-hacerse la agenda política para adaptarla a los nuevos desafíos que plantea las nuevas formas de estructuración y organización social y contribuir a la construcción de un mundo mas justo y mas igualitario. Se trataría, en definitiva, de revitalizar el debate, de romper definitivamente fronteras disciplinares, de colocar de una vez por todas a la Psicología Social en la mesa donde se debaten los temas de nuestro tiempo.

\section{Aperturas y efervescencias. elementos de tránsito hacia un paisaje post-construccionista}

No debemos asumir una posición complaciente sólo con la contextualización histórico-cultural de la producción del conocimiento, la asunción el carácter interpretativo de los seres humanos, o los principios que sustentan una perspectiva construccionista. Asumirlos, pero también eventualmente criticarlos, es lo que nos permitirá sustentar en permanencia una perspectiva crítica en Ciencias sociales y, específicamente, en Psicología social. En los últimos años, cuestionamientos, ideas nuevas, propuestas distintas, así como nuevas prácticas están ejerciendo una influencia enorme en las nuevas formas de pensar. La sociología del conocimiento científico, la Actor Network Theory (ANT) (Law y Hassard, 1999), que traduciré como "teoría de la actriz-red, la epistemología feminista y la noción de performatividad, son posiciones en estos debates que pueden ser aprovechadas en la empresa de mantener una Psicología Social crítica. 


\section{La reflexividad como característica de la producción de conocimiento}

Desde las aportaciones de la Sociología del Conocimiento Científico, sabemos que el/a investigador/a lo es en la medida en que se relaciona con objetos y sujetos en su actividad, y lo que surge en esa relación es un producto que si en parte está predeterminado por la naturaleza de los objetos y sujetos sociales (construcciones socio-históricas), tiene un componente impredictible y creativo, producto de elementos contingentes, indexicales y circunstanciales del contexto donde acontece la acción. Esto permite modificar el conocimiento de los objetos (en el transcurso que va desde su presentación hasta después de mantener una relación con ellos) y permite que como investigadores podamos modificarnos e ir cambiando, es decir, tengamos una capacidad de agencia, o lo que es lo mismo, el poder de utilizar otras posiciones y elementos intersubjetivos de definición y acción que movilicen otros discursos y que anulen ciertas categorías socialmente predominantes.

\section{La teoría de la actriz-red (Actor network theory)}

La teoría de la actriz-red ha reconocido el valor positivo de las aportaciones del socioconstruccionismo pero argumenta que ha comportando como efecto un "esencialismo social" que ha asumido de forma acrítica la dicotomía natural/social, humano/no-humano y la separación de lo natural por un lado y lo social por otro (Doménech, 1998). Atribuye también al socioconstruccionismo desatención a cuestiones como las relativas a en qué consiste exactamente lo social, cuál es le papel de las ciencias en su constitución y por qué ha devenido objeto de estudio y conocimiento.

En el nuevo panorama post-construccionista la ANT nos descubre las implicaciones que el dualismo natural-social tiene y nos abre un campo nuevo de posibilidades de conceptualización de agentes, sujetos u objetos. Entre otras, nos permite equilibrar el balance entre lo natural-social recolocando lo material y creando una nueva hibridación conceptual alejada de esencialismos culturalistas o materialistas.

\section{Posicionamientos: las consecuencias de la epistemología feminista}

El escenario actual de las Ciencias sociales y humanas no sería lo que es sin las aportaciones de la epistemología feminista. Ha cuestionado y puesto de manifiesto la relación íntima e inextricable existente entre un sujeto que percibe y aborda la comprensión de un objeto, y el objeto concreto sobre el que enfoca su mirada.

Ningún objeto es neutro, está teñido y atravesado por significados e implícitos, y la mirada con que se aborda, la epistemología y metodologías que lo "desentrañan", es una mirada de género. Todo ello no es sino una prueba más de que el modelo de conocimiento de las sociedades occidentales es ideológico, y que procede y se contrasta fundamentalmente a partir de las experiencias masculinas. Tal como sostiene Evelyn Fox Keller (1985), la presunta neutralidad y objetividad de la ciencia, en sus aspectos psicológico y cognitivo, es una construcción masculina. Un sujeto de conocimiento es un sujeto con una preconcepción del mundo, no un individuo abstracto, ahistórico e incorpóreo. Por tanto, la subjetividad está situada y se encuentra tanto en el sujeto como en el objeto, así como en la relación que se establece entre ellas.

La perspectiva epistemológica feminista critica toda teoría que se pretenda universal. Para ello, se basa en la subjetividad y la concepción fragmentada de las subjetividades (Donna Haraway, 1991), lo que en el ámbito de la epistemología significa tener en cuenta las particularidades de los sujetos de 
conocimiento y del propio objeto del mismo. Así pues, utilizar las producciones y formulaciones de la epistemología feminista implica considerar que cualquier teoría de la ciencia no puede establecer de manera estándar la comprensión de su objeto de estudio sin reflexionar acerca de quién es el sujeto de conocimiento, qué posición ocupa, cómo está influyendo el género en los métodos utilizados y, una cuestión central, qué podemos entender por ciencia.

La riqueza de la epistemología feminista radica en su claro posicionamiento de crítica social. Los principios orientadores de las teorías y prácticas feministas se han materializado en duras críticas hacia los procesos sociales, políticos, históricos de desigualdad y dominación. El concepto de transformación de las relaciones sociales sigue teniendo su vigencia desde las primeras formulaciones y sigue siendo el motor de orientación de todos sus desarrollos teórico-conceptuales. Pero el pensamiento feminista no ha conseguido únicamente cambios en los planos vistos hasta el momento. Para una agenda postconstruccionista otras aportaciones son también extraordinariamente importantes. En particular, me referiré a continuación a la performatividad.

\section{Performatividad}

Como sabemos, una de las críticas mas crudas al construccionismo ha consistido en atribuirle un cierto idealismo lingüístico. No hay problema en reconocer que al enfatizar la importancia del lenguaje y la naturaleza discursiva de las prácticas sociales, el socioconstruccionismo ha contribuido a desencializar, denaturalizar y des-psicologizar al individuo y a los procesos psico-sociales. Pero seguramente eso también le ha llevado a desatender lo que podría ser llamado "prácticas no lingüísticas". No es el caso de todo el construccionismo, pues una lectura foucaultiana del discurso y la práctica discursiva no anula ni desprecia la materialidad, sino que más bien la re-coloca en otro lugar del escenario. No obstante, siempre se puede decir que quizás se ha ignorado en demasía el efecto de objetos y materialidades que generan sus efectos utilizando medios no estrictamente lingüísticos.

La emergencia del llamado "pensamiento queer" o "teoría queer" (Llamas, 1998; Preciado, 2002) y específicamente el enfoque de la performatividad de Judith Butler, ayuda a subsanar este problema y a abrir un campo nuevo de interés, cual es la subjetivación y las prácticas de subjetivación y a ofrecer nuevos elementos en una agenda política radical.

Judith Butler ha perfilado la noción de performatividad. Máxima representante de la "teoría queer", su planteamiento viene a revolucionar las nociones de identidad, subjetividad y prácticas de subjetivación que se ilustra en su análisis-propuesta en torno a la producción preformativa de la identidad sexual. Se trata de una posición antiesencialista que niega tanto el carácter natural de la identidad como su carácter fijo y estable. La identidad es una construcción social, efectivamente, pero una construcción que debe entenderse como un proceso abierto a constantes transformaciones y redefiniciones.

Este el planteamiento de Judith Butler viene a ofrecer una alternativa tanto a la noción de construcción social como a los límites de la discursividad. En efecto, siguiendo a Butler, la cuestión no es si todo es una construcción social o si todo se construye discursivamente, porque cuando se plantean las cosas así, se está negando la fuerza constitutiva de la performance. Lo que Butler está proponiendo es una noción de construcción que implica una especie de "vuelta" a la materia. Pero una materia que no es sitio o superficie como ella misma dice, sino materia como "proceso de materialización que se estabiliza a través del tiempo para producir el efecto frontera, de permanencia y de superficie que llamamos materia" (Butler, 1993:28). Paralelamente, la construcción no es vista como un acto único o como un proceso de tipo causal iniciado por un sujeto del cual se deriven efectos. Mas bien, la construcción "no 
sólo se realiza en el tiempo, sino que es en sí mismo un proceso temporal que opera a través de la reiteración de normas" (Butler, 1993:29)

\section{El mantenimiento de una psicología social crítica}

Hasta aquí he descrito brevemente algunos elementos característicos del construccionismo social, algunos de los problemas que se le plantean, así como el esbozo de nuevas tendencias y orientaciones que se han ido gestando en los últimos años, a veces en paralelo y otras al lado del construccionismo. Todo ello permite, creo, rediseñar la caja de herramientas para una "refundación" de una perspectiva crítica. En este sentido, pretende ser una contribución más a una perspectiva que ha sido etiquetada unas veces como "Psicología Social Crítica".

Una "Psicología social crítica" sería la consecuencia de un continuo cuestionamiento y problematización de las prácticas de producción de conocimiento y por tanto tiende a recoger la mayor parte de las características que he enunciado, es decir, la historicidad del conocimiento, el carácter interpretativo del ser humano, un punto de vista construccionista, la reflexividad del conocimiento, las aportaciones de la epistemología feminista y del conocimiento situado, la eclosión de los estudios sociales de la ciencia y la tecnología, la performatividad, etc. Sin embargo, si hasta hace poco tanto en lo que se refiere a las asunciones ontológicas, como epistemológicas, metodológicas, políticas, etc. esta perspectiva se integraba en ese movimiento de tipo general que podemos denominar "construccionista", hoy se puede decir que se expande en la eclosión de perspectivas del nuevo paisaje postconstruccionista y que se enrola en el proyecto/intento de permeabilización de las disciplinas científico-sociales, convirtiéndose en un magma informe que impregna lugares y recovecos en el ámbito genérico de las humanidades y las ciencias sociales.

Hoy día, además de todo eso, se puede decir que los ejes ya no son tales, sino mas bien una malla donde los nudos son acontecimientos y posicionamientos inestables y sus hilos, conceptos híbridos de difícil si no imposible etiquetación. En consecuencia, la acción de producir conocimiento, ya se enmarque en el espacio de las ciencias sociales en general o bajo el título específico de psicologia social crítica, no podrá ignorar las nuevas condiciones que la posibilitan así como las consecuencias que desencadenan.

En fin, lo que vamos a ver complementariamente en lo que resta del simposium, son algunos puntos de vista gestados en el interior de la Psicología Social que podrían participar también en esta efervescencia del pensamiento y la ciencia social contemporánea: los planteamientos de Tomás Ibáñez, Pablo Fernández Christlieb y Peter Spink.

\section{Referencias}

Burr, Vivian (1995). Una introducció al construccionisme social. Barcelona: EDIUOC, 1997

Butler, Judith (1993). Cuerpos que importan. Sobre los límites materiales y discursivos del 'sexo'. Buenos Aires: Paidós. 2002.

Doménech, Miquel (1998). El problema de 'lo social' en la Psicología social. Anthropos, 177, 34-39. 
Haraway, Donna J. (1991). Ciencia, cyborgs y mujeres. La reinvención de la naturaleza. Madrid: Cátedra. 1995.

Ibáñez, Tomás (1994). Psicología social construccionista. Guadalajara (México): Universidad de Guadalajara.

Keller, Evelyn Fox (1985). Reflexiones sobre género y ciencia. Valencia: Alfons el Magnànim. 1989.

Law, John y Hassard, John. (Eds.) (1999). Actor network theory and after. Oxford: Blackwell.

Llamas, Ricardo (1998). Teoría torcida. Prejuicios y discursos en torno a 'la homosexualidad'. Madrid: Siglo XXI.

Preciado, Beatriz (2002). Manifiesto contra-sexual. Madrid: Opera prima.

Tajfel, Henry (1972). Experiments in a Vacuum In John Israel \& Henry Tajfel (Eds.) The context of Social Psychology. A Critical Assessment. London: Academic Press. pp.69-119.

\section{Formato de citación}

Íñiguez, Lupicinio (2005). Nuevos debates, nuevas ideas y nuevas prácticas en la psicología social de la era 'post-construccionista'. Athenea Digital, 8, Disponible en http://antalya.uab.es/athenea/num8/siniguez.pdf

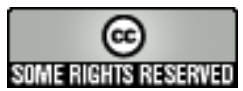

Este texto está protegido por una licencia Creative Commons.

Usted es libre de copiar, distribuir y comunicar públicamente la obra bajo las siguientes condiciones:

Reconocimiento: Debe reconocer y citar al autor original.

No comercial. No puede utilizar esta obra para fines comerciales.

Sin obras derivadas. No se puede alterar, transformar, o generar una obra derivada a partir de esta obra.

\section{$\underline{\text { Resumen de licencia }}$}

$\underline{\text { Texto completo de la licencia }}$ 